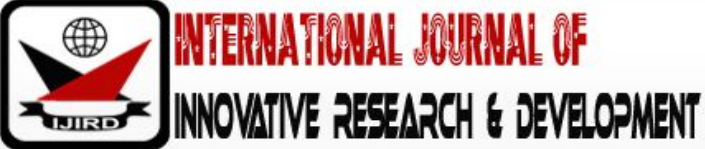

ISSN 2278 - 0211 (Online)

\section{Creativity in Work: An Educational Program for Improving Nurses'Productivity}

\author{
Ebtesam Saeed Ahmed Abd-Elrhaman \\ Lecturer, Department of Nursing Administration, Benha University, Egypt \\ Aya Ghoneimy Hasanin Ghoneimy \\ Lecturer, Department of Nursing Administration, Benha University, Egypt
}

\begin{abstract}
:
Creativity is fundamental for the advancement of nursing practice and turn into a prerequisite for enhancing nursing results. In addition, nurses' creativity assumes critical part as, seeks high value to an organizations' development, productivity and maintainability is entrenched. Productivity is a critical marker of professional development within any professional group, including nurses. Aim: The present study aimed to assess effect of education program about creativity in work on nurses' productivity. Research Design: Quasi experimental design was utilized. Study Setting: the study was conducted in general medical and surgical units at Benha University Hospital. The study sample was: A convenience sample of staff nurses (102) from the above-mentioned setting. Tools of data collection: Four tools were used: (1) Creativity knowledge questionnaire, (2) Attitude toward creativity questionnaire, and (3) Level of creativity questionnaire, (4) Nursing productivity questionnaire. Results: The findings of this study showed that there was highly statistically significant improvement in staff nurses' knowledge and attitude toward creativity thorough program. In addition, there was highly statistically significant improvement in staff nurses ' level of creativity and level of productivity thorough program. Conclusion: The study concluded that that there was a positive highly statistically significant correlation between level of productivity and level of creativity and attitude toward creativity immediate post program. Recommendation: Policymakers nurse educators, nursing and hospital managers should provide a nurturing environment that is conducive to creative thinking, giving the nurses opportunity for flexibility, creativity, support for change, and risk taking for increasing productivity. And nursing faculties should integrate creative thinking education in study courses.
\end{abstract}

Keywords: Creativity, staff nurses, and productivity

\section{Introduction}

Recently, with changing and expanded working settings, nurses repetitively act in unanticipated circumstances in different settings as a serious part of the healthcare sector to deliver holistic care for patients (Chan, 2013). To handle new and exceptional components in these difficult states, nurses must be ready to reply to any challenges in timely, effective, creative and adaptable ways. Creativity isn't new to the nursing career. Its presentation can be followed back to Myra Levine in 1973 and identified it as a daily occurrence which was fundamental to patient-nurse interactions (Murad, 2016). It is a main and a multifaceted issue in nursing profession and the most essential key to development of both human services and nursing. What's more, it is perceived as the formation of novel, appropriate and helpful thoughts. Also, it is the mental work or activity involved in bringing something new. In order for the nurses to be creative; should be equipped for seeing things in new routes or from an alternate point of view, ready to create new potentials or new options, communicate ideas and values (Bruise, 2016).

Additionally, creativity is an attitude to accept change and a readiness to play with ideas and opportunities, a flexibility of viewpoint, the practice of liking the good, while searching for approaches to enhance it. To engage in creative behavior, nurses need management support, resources, supportive work environment, and knowledge about creativity and nurses' role. Accordingly, nurses' creativity does not just rely upon individual qualities and their own creativity. The social or work workplace, education, reward system, and management style can impact both the level and the recurrence of creative behavior (Dul et al., 2011).

Creativity assessment broadly sorts into a few categories of measurements: creative products, creative cognition, creative traits, and creative behavior and accomplishments (Silvia et al., 2012). In any case, it is generally indicated "the four P's" representing the four dimensions of creativity "person, process, press, and product". Firstly; a person centers on the character of creative individuals. Secondly; process is the mechanisms that inspire creative thinking or action. Thirdly; press alludes to environments that interact with the creative person to best carry out creativity. Last items are products outcomes; the most target way to deal with measure creativity (Pujiriyanto,2016). 
Numerous studies had separated between two types of creativity on the beginnings level, those are; technical level; it is identified with production of creative goods and services. While the other one is administrative level; it is related to the administrative process in the organization, and related indirectly to the fundamental actions of the organization (AlSrour,2013). Also, Creativity is commonly three types; namely, individual creativity, group/team creativity and organizational creativity (Chegani, 2016).

Creativity is learned through practice and creative nurses are often exhibit paradoxical qualities as; have a great deal of physical energy, but they're also often quiet and at rest, tend to be smart, but also naive, combine responsibility and irresponsibility, alternate between imagination but realistic dreamers, extroverted and introverted, proud of their achievements and accomplishments yet, modest, are more likely to have not only the strengths of their own gender but those of the other one too, conservative, yet rebellious, passionate, but objective about their work, sensitive and open to experience, but happy and joyful(Tabarestani,2014).

Nurses are a serious element of the healthcare system. The quality of patient care and the productivity and image of a hospital are specifically reliant on them, and play a major role in the organization's success (Malik and Dhar, 2016). Hence, nurses' productivity is the heartbeat of organization's success, as affecting organizational total factor productivity. Health care organizations cannot succeed without productive nursing staff. Productivity is known as the ratio of outputs to inputs (Finkelman, Kenner, 2013). While, nursing productivity is generally defined as the ratio of patient care hours per patient day to salary and benefit costs paid out to staff by the organization (Kohr et al., 2012). Others see nurse productivity as associated with both efficiency of use of clinical nursing in delivering nursing care and the effectiveness of that care related to its quality and appropriateness (Roussel, 2011).

In any case, the diverse techniques for characterizing productivity make its estimation unparalleled. There are numerous qualitative methods" conventional " to measure productivity, which contain the following; nursing hours per patient day (NHPPD); it mirrors the number of paid nursing care hours used in a day divided by the total number of patient days of care in a given health care setting (Kelly, Tazbir, 2013).

$$
\text { Nursing hours per patient day (NHPPD) }=\frac{\text { Total paid hours for nursing personnel for time }(\mathrm{x})}{\text { Total number of patient days in time }(\mathrm{X})}
$$

Another one, nursing salary costs per patient day; it computes the nursing cost per patient day for every patient utilizing patient day to disperse the cost at that point ascertain the nursing cost per patient day for every patient utilizing nursing hours used to appoint the cost (Jenkins \& Welton, 2014).

\footnotetext{
Total payroll expenses for nursing personnel for time (x)

Total number of patient days in time(X)
}

The utilization of the conventional productivity measurement strategies requires gathering quantitative information from tasks, that is may not be pertinent and troublesome or even difficult to gather the information that is required for productivity measurement. An elective approach for the conventional methods is subjective productivity measurement (SPA) centered on personnel's subjective assessments" e.g., using questionnaires" (Jääskeläinen and Laihonen 2013 \& Massy et al 2013).Decreasing productivity brings about; damages of income, price rises, joblessness, bring down life quality, and reductions in social safety. Though, expanding productivity makes the best utilization of an organization's physical and moral resources, and therefore, it makes the best of the organization's potential capacities, aptitudes and services, which guarantee its survival and improve achievements (Marasingha, 2012; Marquis \& Huston, 2015)

In all, the nursing staff could achieve their job with high productivity and quietly and get great outcomes for their organization, so typically, it is important to be in a workplace which is physically and mentally sound and reasonable as; light, ventilation, and separation from noise and so on, and accessibility of instruments that appropriate for work environment, compensation, inspiration, and the associations administration should keep its staff fulfilled. Finally, the success of productivity depends on staff creativity (Jokari et al., 2012).

\subsection{Significance of the Study:}

Creativity is the cornerstones of health care in both the general and private sectors as; decreasing duplication of services between and within health care organizations, creating solutions to any obstacles and resolving day-to-day difficulties in this way, enhanced services, techniques, job satisfaction and productivity in the health care setting. In this manner, creative nurses are assumed a main role to increase productivity. The most ideal approach to encourage nurses' creativity is presumably through instruction or education training at the workplace which support nurses to develop their creativity for the adjustment to the dynamic and requesting working conditions in nursing in endlessly extraordinary health facilities (Valentine et al. 2011; Jokari, et al., 2012; Gapar, 2014).

\subsection{Aim of the Study}

This study was aimed to assess effect of educational program about creativity in work on nurses' productivity. 


\subsection{Research Hypotheses}

- There will be significant improvement in nurses 'knowledge, attitude related to creativity in work after implementation of educational program.

- There will be significant improvement in nurses' level of creativity after implementation of educational program.

- Level of productivity will be greatly increased after implementation of educational program.

- There will be a positive correlation between staff nurses 'attitude toward creativity, level of creativity in work, and their productivity level after implementation of educational program.

\section{Subjects and Methods}

\subsection{Research Design}

Quasi experimental design was used to achieve the aim of the present study.

\subsection{Setting} Hospital.

The current study was conducted in six general medical units and four general surgical units at Benha University

\subsection{Subjects}

\subsubsection{Subject Type}

A convenient sample

\subsubsection{Subject Size}

A convenience sample of staff nurses (102) who are working in the above-mentioned study setting. (52) of them working in medical units, (50) of them working in surgical units who have at least one year of job experience, available at the time of study, and agree to participate after clarification of purpose of the study.

\subsection{Tools of Data Collection}

Four tools were used to collect the data of this study: -

\subsubsection{Creativity Knowledge Questionnaire}

A structured questionnaire developed by the researchers based on the review of the related literature (Ariffin et al., 2011; Jokari et al., 2012; Isfahani et al., 2015; Ivanovici ,2016) to assess nurses' knowledge regarding creativity in work. It consisted of two parts, part one; include personal characteristics of nurses as age, sex, department, marital status, educational qualification, previous training regarding creativity, and experience years. Part two: creativity knowledge questionnaire. It consists of 25 questions (true and false "10" questions, matching "5" questions, and multiple choice "10" questions).

\subsubsection{Scoring System}

The questions were scored as "1" for correct answer, and "zero" for incorrect answer. The total scores were summed up and creativity in work knowledge expressed as follow; $<60 \%$ of total score means un satisfactory knowledge and $\geq 60 \%$ of total score mean satisfactory knowledge.

\subsubsection{The Attitude toward Creativity Questionnaire}

A structured questionnaire developed by the researchers through reviewing the related literature as (Dlouhy, 2012; Taylor,2013; Ivanovici, 2016). It included different items to assess staff nurses' attitude toward creativity in work. It consisted of 24 items divided into three main categories; the pattern of creativity at work (5) items, encouragement of creativity by superiors and hospital management (14) items, the constraints that limit creativity at work (15).

\subsubsection{Scoring System}

Using a three-point Likert - scale as follow: never ( 0 point), sometimes (1 point), and always ( 2 point). The score of each dimension summed up and converted to percent score. Attitude toward creativity is considered highly positive if the percent $\geq 75 \%$ (score $\geq 36$ ), positive if the percent $60 \%-<75 \%$ (score 29- <36) and negative if the percent $<60 \%$ (score $<29$ ).

\subsubsection{Level of Creativity Questionnaire}

This tool was developed by the researchers through reviewing the related literatures (Jokari et al., 2012; Isfahani et al., 2015; Ivanovici, 2016). It included different items to assess staff nurses' level of creativity at work, it consisted of (58) items divided into five main categories; general features that characterized personality "19" items, degree of flexibility in work "8" items, sensitivity to solve problem " 14 " items, keeping the direction or goal "11" items, and accepting the risk at work "6" items. 


\subsubsection{Scoring System}

Using a three-point Likert - scale as follow: disagree ( 0 point), neutral (1 point), and agree ( 2 point). the score of each dimension summed up and converted in to percent score. level of creativity is considered high if the percent $\geq 75 \%$ (score $\geq 87$ ), moderate:60\%- 74\% (score 70 - 86) and low: <60\% (score <70).

\subsubsection{Nursing Productivity Questionnaire}

It was adopted by Abdulla (2014) and aimed to measure staff nurses' level of productivity. It was consisted of 21 items.

\subsubsection{Scoring System}

Using a three-point Likert - scale as follow: never ( 0 point), sometimes (1 point), and always (2 point). The participant who had a percent $\geq 75 \%$ (score $\geq 32$ ), this indicate high level of productivity, participant who had the percent from $60 \%-74 \%$ (score $25-<32$ ) indicate moderate level of productivity, and the participant who had a percent $<60 \%$ (score $<25)$ this indicated low level of productivity.

\subsection{Methods}

The study was executed according to the following steps

\subsubsection{Approval}

An official permission was obtained from the hospital authorities in the identified setting to collect the necessary data and implement the program after explaining its purpose.

\subsubsection{Pilot study}

A pilot study was carried out on 10\% from the total number of studied subjects (10) staff nurses who were included in the main study sample to ascertain the tools clarity, applicability, objectivity and feasibility as well as detect any problem peculiar to the statements such as sequence and clarity that might interfere with the process of data collection also, estimate the time needed for filling the tools. The pilot study was included in the main study sample.

\subsubsection{Tools Validity and Reliability}

The tools were reviewed by panel of experts from different nursing departments. The panel ascertained the face and content validity of the tools. The reliability was done by Cronbach's Alpha coefficient test. Cronbach's alphas were $(\mathrm{r}=$ $0.89,0.90,0.86 \& 0.91$ ) creativity knowledge questionnaire, attitude toward creativity questionnaire, level of creativity questionnaire, and nursing productivity questionnaire respectively.

\subsubsection{Ethical Considerations}

Approvals of staff nurses were obtained before data collection and after informed about the purpose and benefits of the study then oral consent was obtained before starting the data collection. Anonymity was assured as the filled questionnaire sheets were given a code number (not by names). Confidentiality was ensured throughout the study. The studied subjects were assured that all data was used only for research purpose and questionnaire sheet will be discarded at the end of the study and were informed of their rights to refuse or withdraw at any time of the study.

\subsubsection{Educational Program about Creativity in Work}

This program was designed to provide staff nurses an opportunity to enhance their creativity at work. It covered the following items; concept of creativity, importance of creativity, personality traits that characterize the creators, characteristics of creativity, the creative capacity, the motives of creativity, levels of creativity, management practices that affect creativity, obstacles to creativity, and the role of managers to deal with the obstacles to creativity.

\subsubsection{Field Work} following:

The study was carried out for (Nine months) from at the beginning of May, 2017 to the end of January, 2018 as the

- Pre-implementation phase (Initial assessment): that took about one month from the beginning of May, 2017 to the half of June, 2017. Teaching materials was prepared and the training strategy was developed based on the detected needs. As well, time schedule, teaching sessions, media included, and the handout were prepared.

- Implementation phase (intervention): was carried out from the half of June, 2017 to end of August, 2017. First staff nurses were divided into (10) small groups (10-11 nurses) according to their units. The preprogram tests were fulfilled by the staff nurses before beginning of the training program. Creativity knowledge questionnaire took from 15-20 minutes to be completed, and 20-25 minute for completing attitude toward creativity questionnaire and 25-30 minutes for completing level of creativity questionnaire, also, 15-20 minutes for completing nursing productivity questionnaire. This pre-study test was designed to allow the researchers collect a baseline assessment of nurses' knowledge and skills in order to compare it with immediate post and follow-up program. The data collected five days/ week in the morning and afternoon from the half of June, 2017 to half of July, 2017.

- After the questionnaires were completed, the training program was implemented by the researchers. The time plan of the program implemented over the period from the half of July, 2017 to end of August, 2017. The training program has taken 12 hours for each group distributed as the following; 6 sessions, 2hour/ session, 3days/ week in 
the morning and afternoon shift. Each group perceived the program content using the same teaching strategies and handout. Each researcher implements the program with two groups in the day, except the last two week each researcher implements the program with one group in the day by using the same available resources, relevant contents and instructional strategies for each session. Different methods of teaching were used such as lectures, group discussion, and brainstorming. Instructional media included handout prepared by the researchers and distributed to all participants in the first day of implementing the program.

- Evaluation phase: - during this phase, the effect of educational program was evaluated; it was carried out immediately after the program implementation and follow up after 3 months of intervention by using the same format of tools which used before the program implementation. The time of the data collection lasted for five months from the beginning of September, 2017 to end of January, 2017.

\subsubsection{Statistical Analysis}

Analysis of data was carried out by the researcher, Data was verified prior to computerized entry and categorized, coded, computerized, tabulated using IBM SPSS (statistical package for social science) statistical software version (21). Descriptive statistics were applied (e.g., frequency, percentages, mean, and standard deviation). Test of significance Chisquare "X2" and correlation coefficient ( $r$ ) were used. A significant level value was considered when $p<0.05$ and A highly significant level value was considered when $p<0.01$. No statistical significance difference when $p>0.5$. Limitation of the study: - Lack of local researches that study the current research

\section{Results}

- $\quad$ Table (1): Showed that there was more than one third of staff nurses (36.3\%) had age from 30 to less than 35 years old with a mean age of (32.38 \pm 8.2$)$ years. While the majority of them $(87.3 \%, 91.1 \%)$ were female and married respectively. As regarding to qualification, half of staff nurses (50.0\%) had nursing diploma, and more than half of them (51.0\%) worked in medical department. According to years of experience, $38.3 \%$ of staff nurses had years of experience from 10 to 15 years with a mean year of experience (12.85 \pm 7.18$)$.

- Figure (1): Illustrated that there was highly statistically significant improvement in staff nurses` knowledge scores regarding creativity in work immediate post program (80.4\%) and three months follow up the program (66.7\%) than preprogram scores (13.7\%).

- Table (2): Clarified that the highest percent of staff nurses had low creativity level regarding keep the direction or goal followed by degree of flexibility in the work $(94.1 \%$ \& $90.2 \%)$ respectively for preprogram. While immediate post program, the highest percent of them had high creativity level regarding sensitivity to solve problems followed by general features that characterize personality $(83.3 \% \& 80.4 \%)$ respectively. In addition, there was a highly statistically significant improvement in staff nurses ' level of creativity scores regarding creativity in work thorough the program.

- Figure (2): Illustrated that there was highly statistically significant improvement in staff nurses ' level of creativity in work immediate post program (77.5\%) and three months follow up the program $(64.7 \%)$ compared to preprogram scores.

- Table (3): Demonstrated that the majority of staff nurses had negative attitude toward creativity for preprogram. While immediate post program, the highest percent of them had highly positive attitude toward creativity regarding the pattern of creativity at work followed by the constraints that limit creativity at work $(44.1 \%$ \& $37.3 \%)$ respectively. Moreover, there was a highly statistically significant improvement in staff nurses' attitude toward creativity scores thorough the program.

- Figure (3): Portrayed that there was highly statistically significant improvement in staff nurses`attitude toward creativity immediate post program $(77.5 \%)$ and three months follow up the program $(14.7 \%)$ compared to preprogram scores.

- Figure (4): showed that there was highly statistically significant improvement in staff nurses` level of productivity immediate post program (84.3\%) and three months follow up the program (63.7\%) compared to preprogram scores.

- Table (4): Clarified that there was a positive highly statistically significant correlation between level of creativity, attitude toward creativity, level of productivity and experience, qualification of studied staff nurses during immediate post program phase.

- Table (5): Clarified that there was a positive highly statistically significant correlation between staff nurse' level of creativity and attitude toward creativity immediate post program. Also, that there was a positive highly statistically significant correlation between level of productivity and level of creativity and attitude toward creativity immediate post program. 


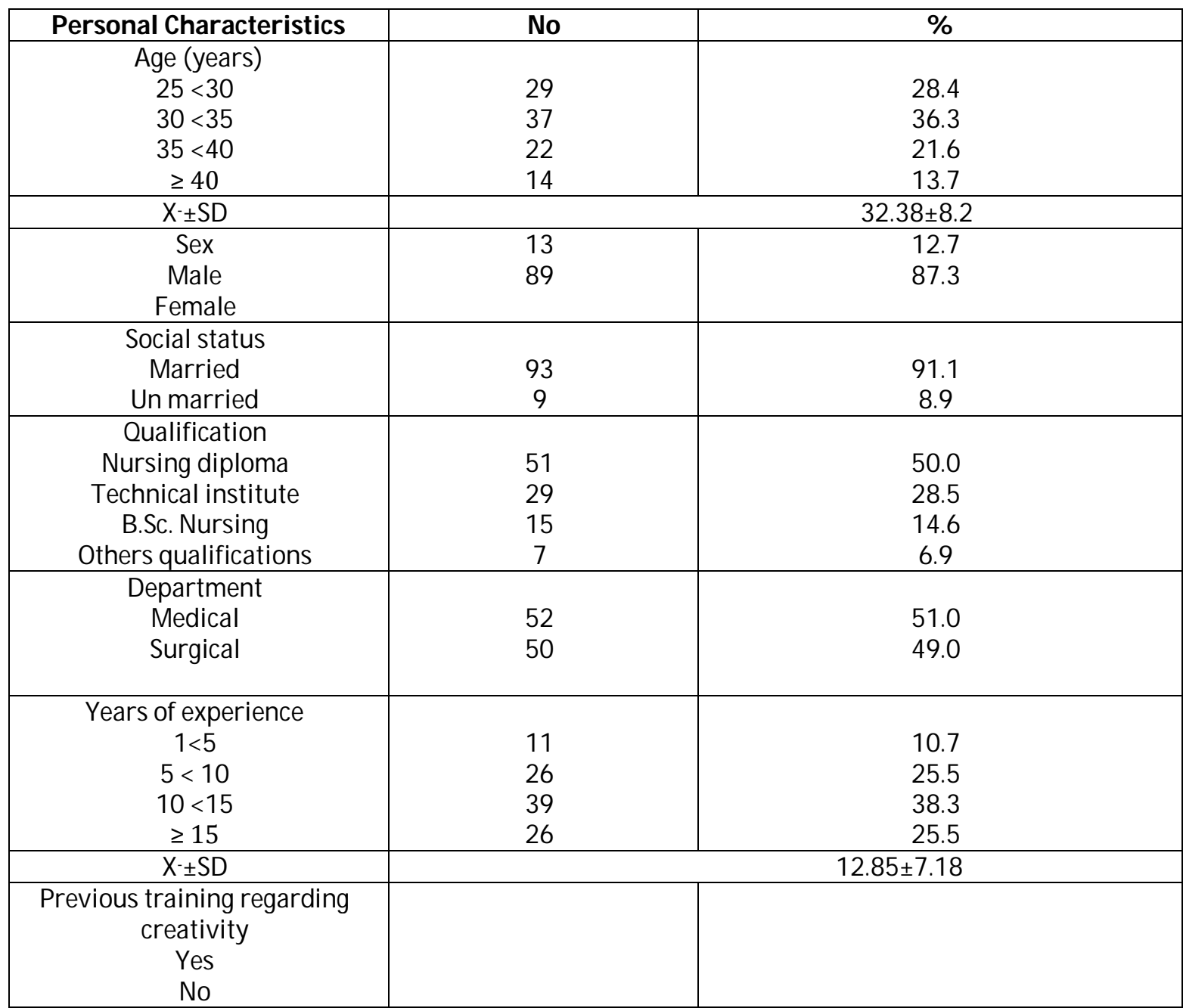

Table 1: Distribution of the Studied Staff Nurses According to Their Personal Characteristics ( $\mathrm{N}=102$ )

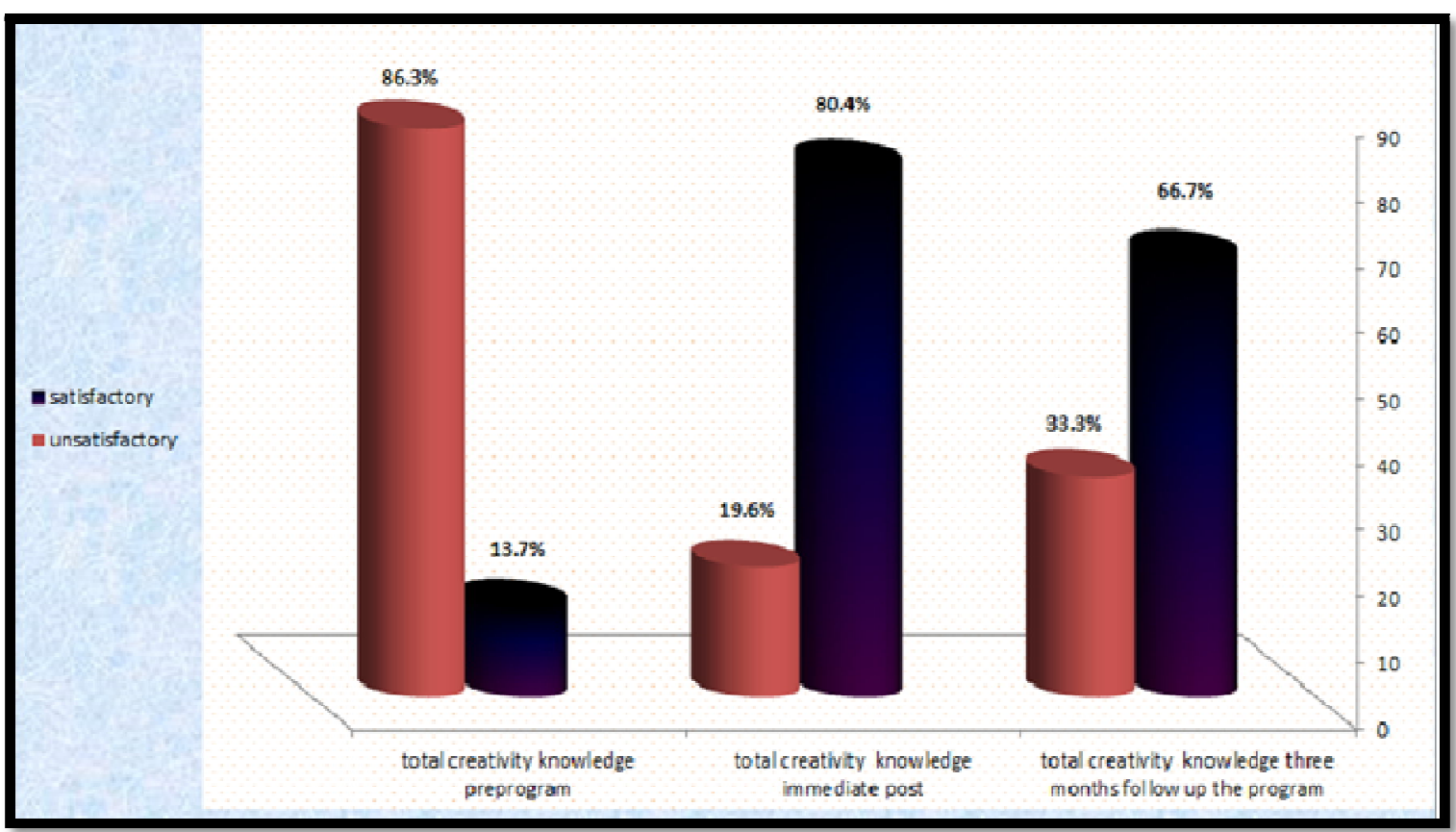

Figure 1: Level of Studied Nurses' Knowledge about Creativity in Work (N=102) 


\begin{tabular}{|c|c|c|c|c|c|c|c|c|c|c|}
\hline \multirow{3}{*}{$\begin{array}{l}\text { Level of Creativity in } \\
\text { Work }\end{array}$} & \multicolumn{6}{|c|}{ Staff Nurses $(n=102)$} & \multirow{3}{*}{$\begin{array}{c}\mathbf{X}^{2} \\
\text { Test } \\
\text { (1) }\end{array}$} & \multirow{3}{*}{ P-Value } & \multirow{3}{*}{$\begin{array}{c}X^{2} \\
\text { Test } \\
\text { (2) }\end{array}$} & \multirow{3}{*}{ P-Value } \\
\hline & \multicolumn{2}{|c|}{ Pre-program } & \multicolumn{2}{|c|}{ Post-program } & \multicolumn{2}{|c|}{$\begin{array}{l}\text { Follow up- } \\
\text { program }\end{array}$} & & & & \\
\hline & No & $\%$ & No & $\%$ & No & $\%$ & & & & \\
\hline \multicolumn{2}{|c|}{$\begin{array}{c}\text { General features that } \\
\text { characterize personality }\end{array}$} & & & & & & \multirow{20}{*}{202.19} & \multirow{20}{*}{$<0.001 * *$} & \multirow{20}{*}{188.62} & \multirow{20}{*}{$<0.001^{* *}$} \\
\hline High creative & 0 & 0.0 & 82 & 80.4 & 64 & 62.7 & & & & \\
\hline Moderate creative & 26 & 25.5 & 9 & 8.8 & 12 & 11.8 & & & & \\
\hline Low creative & 76 & 74.5 & 11 & 10.8 & 26 & 25.5 & & & & \\
\hline \multicolumn{2}{|c|}{ Degree of flexibility in the work } & & & & & & & & & \\
\hline High creative & 0 & 0.0 & 78 & 76.6 & 67 & 65.7 & & & & \\
\hline Moderate creative & 10 & 9.8 & 8 & 7.8 & 14 & 13.7 & & & & \\
\hline Low creative & 92 & 90.2 & 16 & 15.6 & 21 & 20.6 & & & & \\
\hline \multicolumn{3}{|c|}{ Sensitivity to solve problems } & & & & & & & & \\
\hline High creative & 0 & 0.0 & 85 & 83.3 & 76 & 74.5 & & & & \\
\hline Moderate creative & 21 & 20.6 & 10 & 9.8 & 15 & 14.7 & & & & \\
\hline Low creative & 81 & 79.4 & 7 & 6.9 & 11 & 10.8 & & & & \\
\hline \multicolumn{7}{|c|}{ Keep the direction or goal } & & & & \\
\hline High creative & 0 & 0.0 & 74 & 72.6 & 61 & 59.8 & & & & \\
\hline Moderate creative & 6 & 5.9 & 8 & 7.8 & 10 & 9.8 & & & & \\
\hline Low creative & 96 & 94.1 & 20 & 19.6 & 31 & 30.4 & & & & \\
\hline \multicolumn{7}{|c|}{ Accept the risk at work } & & & & \\
\hline High creative & 0 & 0.0 & 77 & 75.5 & 65 & 63.7 & & & & \\
\hline Moderate creative & 14 & 13.7 & 5 & 4.9 & 8 & 7.8 & & & & \\
\hline Low creative & 88 & 86.3 & 20 & 19.6 & 29 & 28.5 & & & & \\
\hline
\end{tabular}

Table 2: Comparisons of Creativity Level among Studied Staff Nurses Thorough Program (N=102)

**A High Statistically Significant Difference $(\mathrm{P} \leq 0.001)$

X2 \& P Value Test (1): between Pre-Program and Immediate Post Program X2 \& P Value Test (2): between Pre Program and Follow up Program

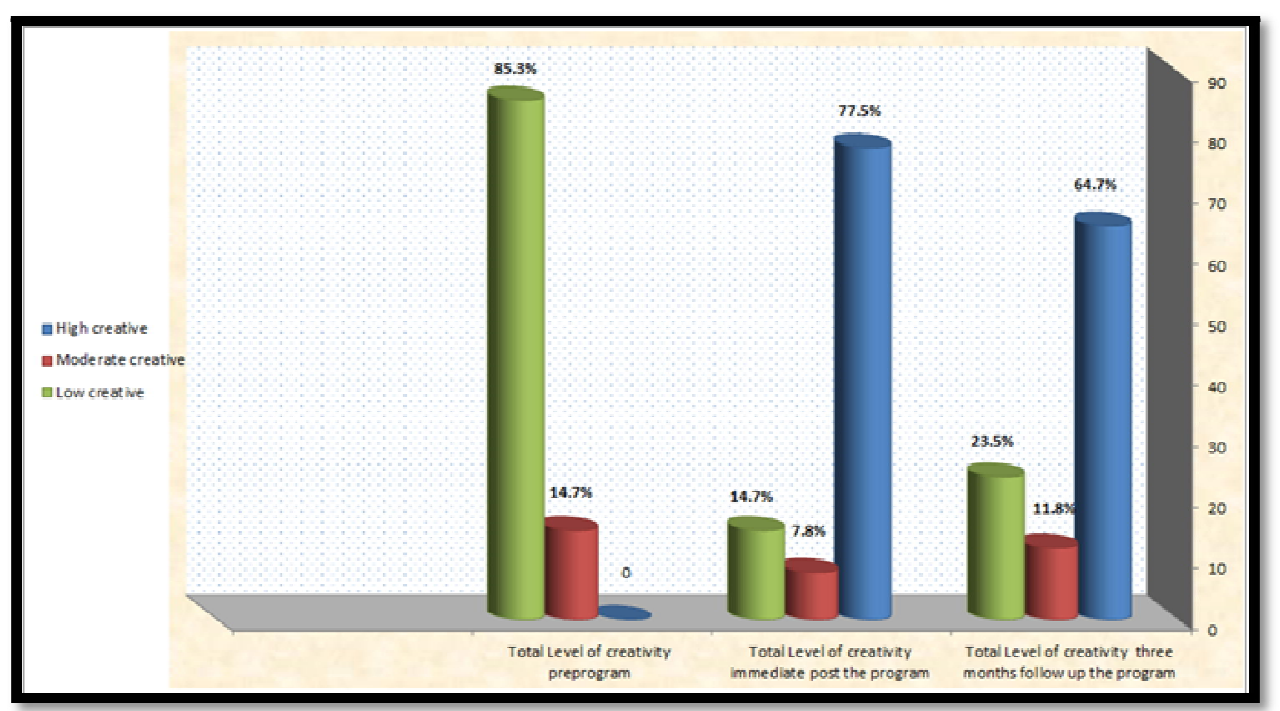

Figure 2: Total Level of Creativity in Work among Studied Staff Nurses thorough Program (N=102) 


\begin{tabular}{|c|c|c|c|c|c|c|c|c|c|c|}
\hline \multirow{3}{*}{ Attitude Toward Work } & \multicolumn{6}{|c|}{ Staff Nurses $(\mathrm{N}=102)$} & \multirow{3}{*}{$\begin{array}{c}\mathrm{X}^{2} \\
\text { Test } \\
\text { (1) }\end{array}$} & \multirow{3}{*}{$\begin{array}{c}\text { P- } \\
\text { Value }\end{array}$} & \multirow{3}{*}{$\begin{array}{c}\mathrm{X}^{2} \\
\text { Test } \\
\text { (2) }\end{array}$} & \multirow{3}{*}{ P-Value } \\
\hline & \multicolumn{2}{|c|}{ Pre-program } & \multicolumn{2}{|c|}{ Post-program } & \multicolumn{2}{|c|}{$\begin{array}{l}\text { Follow up- } \\
\text { program }\end{array}$} & & & & \\
\hline & No & $\%$ & No & $\%$ & No & $\%$ & & & & \\
\hline The pattern of creativity a & & & & & & & \multirow{12}{*}{189.7} & \multirow{12}{*}{$\begin{array}{c}\varangle 0.001 * \\
*\end{array}$} & \multirow{12}{*}{171.6} & \multirow{12}{*}{$\varangle 0.001^{* *}$} \\
\hline Highly positive & 0 & 0.0 & 45 & 44.1 & 18 & 17.6 & & & & \\
\hline Positive & 7 & 6.8 & 42 & 41.1 & 60 & 58.8 & & & & \\
\hline Negative & 95 & 93.2 & 15 & 14.8 & 24 & 23.6 & & & & \\
\hline \multicolumn{7}{|c|}{ Encouraging creativity by superiors } & & & & \\
\hline Highly positive & 0 & 0.0 & 27 & 26.5 & 16 & 15.7 & & & & \\
\hline Positive & 13 & 12.7 & 53 & 51.8 & 49 & 48.0 & & & & \\
\hline Negative & 89 & 87.3 & 22 & 21.7 & 37 & 36.3 & & & & \\
\hline \multicolumn{7}{|c|}{ The constraints that limit creativity at work: } & & & & \\
\hline Highly positive & 0 & 0.0 & 38 & 37.3 & 12 & 11.7 & & & & \\
\hline Positive & 17 & 16.7 & 50 & 49.0 & 56 & 55.0 & & & & \\
\hline Negative & 85 & 83.3 & 14 & 13.7 & 34 & 33.3 & & & & \\
\hline
\end{tabular}

Table 3: Comparisons of Attitude toward Creativity among Studied Staff Nurses thorough Program (N=102).

**A High Statistically Significant Difference $(\mathrm{P} \leq 0.001)$

$X 2 \&$ P Value Test (1): between Pre-Program and Immediate Post Program X2 \& P Value

Test (2): between Pre-Program and Follow Up Program

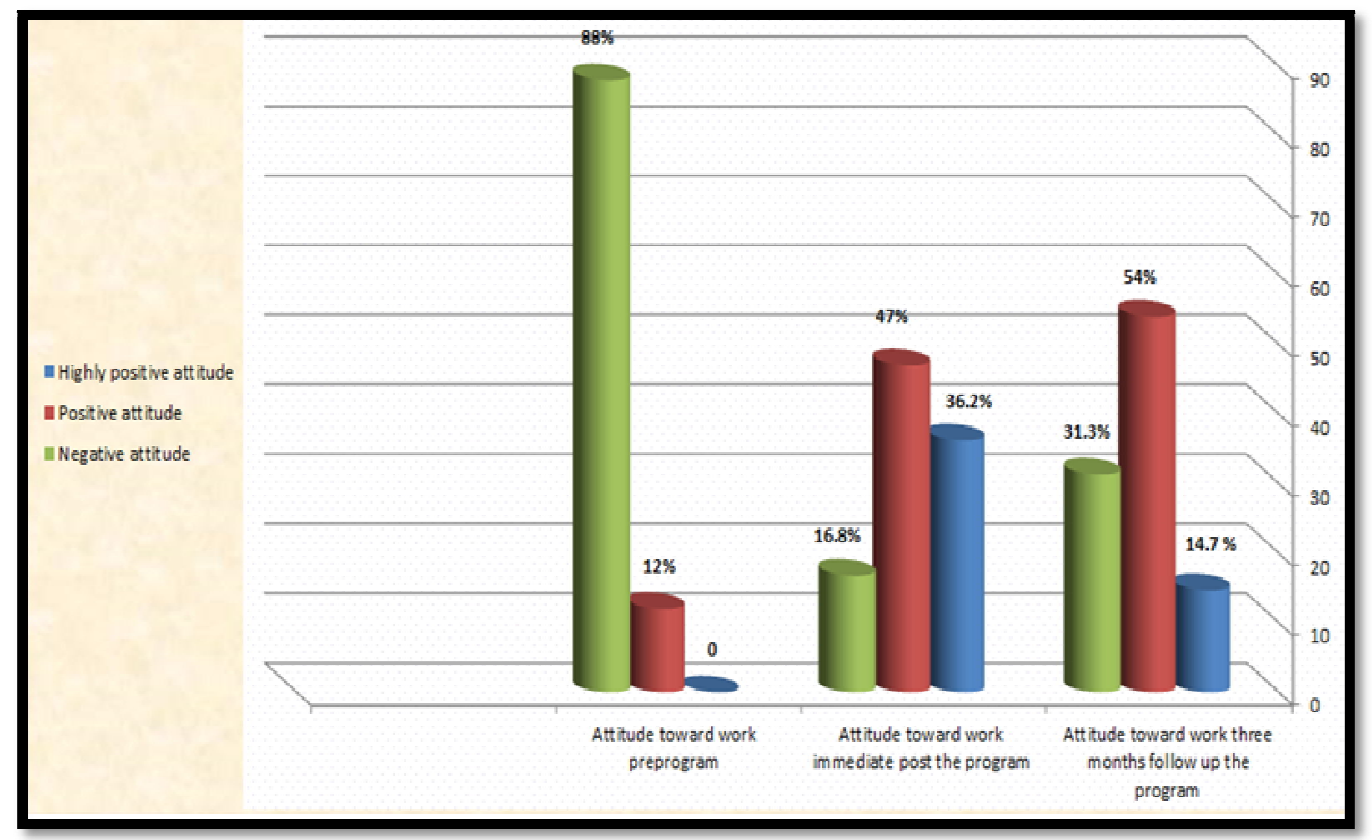

Figure 3: Total Staff Nurses' Attitude toward Creativity thorough Program (N=102) 


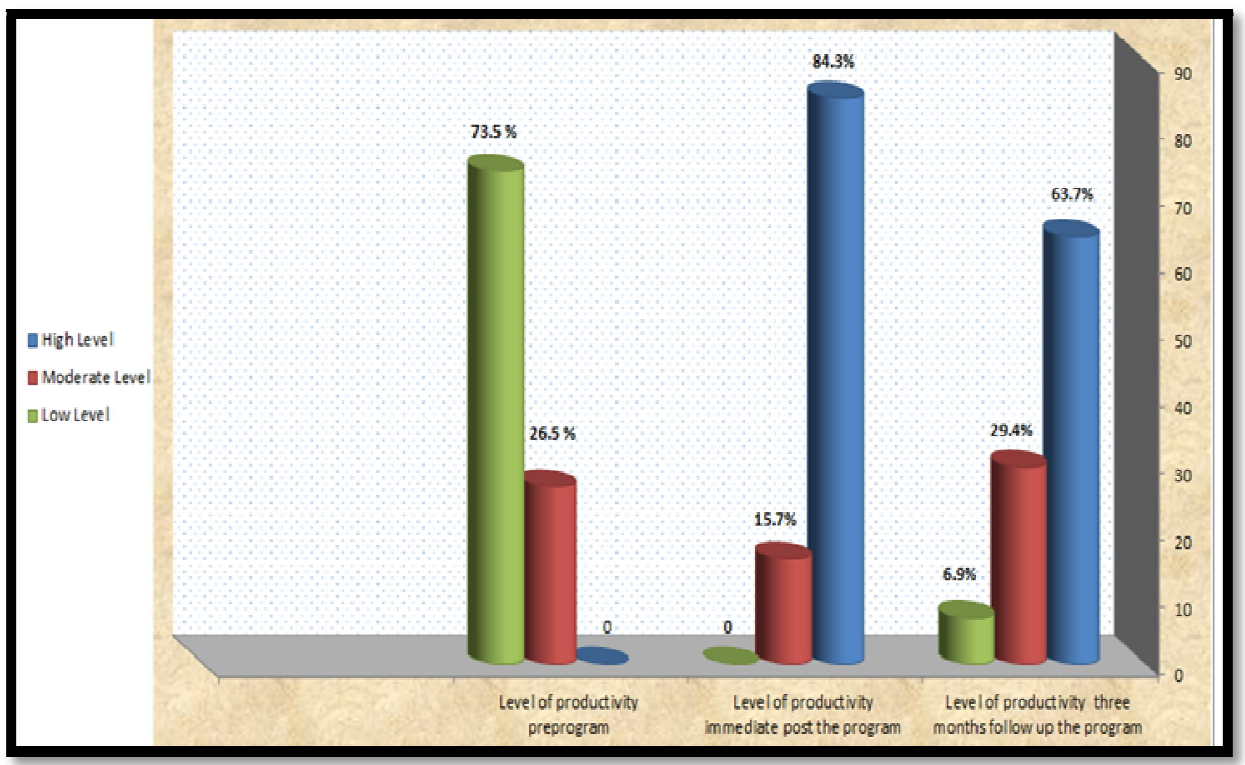

Figure 4: Total Level of Productivity as Reported by

Studied Staff Nurses' thorough Program (N=102)

\begin{tabular}{|c|c|c|c|c|}
\hline \multirow{2}{*}{ Items } & \multicolumn{4}{|c|}{ Personal Characteristics } \\
\cline { 2 - 5 } & \multicolumn{2}{|c|}{ Experience } & \multicolumn{2}{c|}{ Qualification } \\
\cline { 2 - 5 } & $\mathrm{r}$ & $\mathrm{P}-$ value & $\mathrm{r}$ & $\mathrm{P}$ - value \\
\hline Level of creativity & $0.658^{* *}$ & $<0.001^{* *}$ & $0.314^{* *}$ & $<0.001^{* *}$ \\
\hline Attitude toward creativity & $0.340^{* *}$ & $<0.001^{* *}$ & $0.435^{* *}$ & $<0.001^{* *}$ \\
\hline Level of Productivity & $0.575^{* *}$ & $<0.001^{* *}$ & $0.601^{* *}$ & $<0.001^{* *}$ \\
\hline
\end{tabular}

Table 4: Correlation between Level of Creativity, Attitude toward Creativity, Level of Productivity and Experience, Qualification of Studied Staff Nurses during Immediate Post Program Phase ( $\mathrm{N}=102)$ **A High Statistically Significant Difference $(\mathrm{P} \leq 0.001)$

\begin{tabular}{|c|c|c|c|c|c|c|}
\hline \multirow{2}{*}{ Items } & \multicolumn{2}{|c|}{$\begin{array}{c}\text { Attitude Toward } \\
\text { Creativity }\end{array}$} & \multicolumn{2}{c|}{$\begin{array}{c}\text { Level of } \\
\text { Productivity }\end{array}$} & \multicolumn{2}{c|}{ Level of Creativity } \\
\cline { 2 - 7 } & $\mathrm{r}$ & $\mathrm{P}-$ value & $\mathrm{R}$ & $\mathrm{P}$ - value & $\mathrm{r}$ & P- value \\
\hline Level of creativity & $0.398^{* *}$ & $<0.001^{* *}$ & $0.376^{* *}$ & $<0.001^{* *}$ & - & - \\
\hline $\begin{array}{c}\text { Attitude toward } \\
\text { creativity }\end{array}$ & - & - & $0.315^{* *}$ & $<0.001^{* *}$ & $0.398^{* *}$ & $<0.001^{* *}$ \\
\hline Level of Productivity & $0.315^{* *}$ & $<0.001^{* *}$ & - & - & $0.315^{* *}$ & $<0.001^{* *}$ \\
\hline
\end{tabular}

Table 5: Correlation between Level of Creativity, Attitude toward Creativity and Level of Productivity among Studied Staff Nurses During Immediate Post Program Phase (N=102)

**A High Statistically Significant Difference $(\mathrm{P} \leq 0.001)$

\section{Discussion}

Creativity is important to any business, including health care practice, in both the public and private sectors. Problem solving at work often involves finding new and useful ideas, but creative solutions can enhance productivity and job satisfaction in the health care setting Creativity in the health care setting can contribute to new or improved services and procedures, alternative or new methods for service delivery and communication (cornerstones of health care), reducing duplication of services between and within health care organizations, developing solutions to service delivery barriers including financial constraints and resolving day-to-day problems (Valentine et al. 2011; Jokari, Jorfi, and Ebadi 2012).

The result of present study indicated that the total number of staff nurses was 102, there was more than one third of staff nurses (36.3\%) had age from 30 to less than 35 years old with a mean age of (32.38 \pm 8.2 ) years. While the majority of them $(87.3 \%, 91.1 \%)$ were female and married respectively. As regarding to qualification, half of staff nurses $(50.0 \%)$ had nursing diploma, and more than half of them (51.0\%) worked in medical department. According to years of experience, $38.3 \%$ of staff nurses had years of experience from 10 to 15 years with a mean year of experience (12.85 \pm 7.18$)$.

This result was inconsistent with Maarouf, (2017) who conducted a study entitled " Career changing as perceived by nurses and its effect on their satisfaction" and found that nearly half of staff nurses (46.3\%) had age from 30 to less

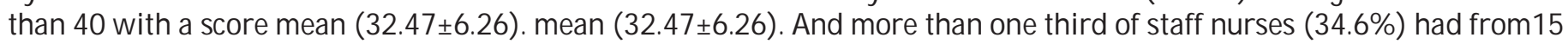
years and more with mean years of experience (13.17 \pm 6.9 ). while Farsi et al., (2014) who conducted a study entitled " Relationship between productivity and burnout in nurses of military hospitals in Tehran" reported that The mean age of 
nurses was $30.95 \pm 5.86$ years (range: 18 - 49 years). About one third of them (31.9\%) aged between $30-35$. In total, $51.2 \%$ of the nurses were male, $84.5 \%$ held a bachelor degree and $72.7 \%$ were married.

Concerning staff nurses' knowledge regarding creativity in work, the result of present study revealed that there was highly statistically significant improvement in staff nurses ' knowledge scores regarding creativity in work immediate post program and three months follow up the program than preprogram scores. This might be due to staff nurses were ready and able to acquire knowledge easily. In addition, creativity topic was very important as staff creativity leads to increased organizational productivity so, they were interested.

These findings were similar El-Shahat (2014), who found in his study done on nursing staff at Benha University Hospital that there was a highly significant improvement in knowledge level throughout the three phases of the program; pre, immediate post program, and follow up after three months, where their knowledge was bad among four fifths of them to completely excellent at immediate post and still excellent in more than three fourths of them.

Regarding staff nurses' level of creativity through the study phases, the result of present study revealed there was a highly statistically significant improvement in staff nurses' levels of creativity scores regarding creativity in work thorough the program. This could be attributed to did not have a chance to be creative or give innovative ideas for updating their job preprogram. Moreover, in our schools did not accustom to learn how to become creative person in all stages of education. While the creativity program was successful and staff nurses learned how to describe and diagnose the problems from all angels accurately by collecting sufficient data and information from several resources to help in putting and choose the best and efficient solution and avoid duplication of efforts and meet the work problems. Moreover, they acquired the skill in debate and dialogue, the ability to quick thinking in various emergency conditions, the power of persuasion when in discussions and having have a private production of new ideas offered in the field of work.

This result was in agreement with Panatik et al., (2016), who conducted a study entitled " The Effect of Personal Factors on Creativity among Research Officers in Malaysia" and revealed that the level of creativity was high among research officers in Malaysia post program application. Also, Kim and Hyunjae (2015) who conducted a study entitled " Level of Creativity and Attitudes Toward an Advertisement" reported that more than two fifth exhibiting a high level of creativity post program, more than one third of them had a medium level of creativity, and more than one fifth had a low level of creativity.

Jabra (2014) reported in his study which done in Jeddah that participants report high level of creativity and more levels of creativity rule is the flexibility and fluency and self-confidence, then the nobility then risk. On the other hand, this finding was inconsistent with Saleh et al. (2013), who conducted a study entitled " Nurse Leaders' Behaviors, and Its Effect on Nurses Creativity and Attitude Toward Change Main Assiut University Hospital" and revealed nurse leaders were below average and average level of creativity at post program, while staff nurses were below average level of creativity.

As regard staff nurses' attitude toward creativity through the study phases, the result of present study revealed that there was highly statistically significant improvement in staff nurses attitude toward creativity immediate post program and three months follow up the program compared to preprogram scores. In addition, the highest percent of them had highly positive attitude toward creativity regarding the pattern of creativity at work followed by the constraints that limit creativity at work immediate post program. This could be attributed to the educational program enable staff nurses tend to translating ideas into simple and specific plans to be implemented, introducing of new and creative ideas without fear of the lack of implementation so it's necessary to have continues training programs to help them to correct all work problems with new and creative solutions and various alternatives.

This result was in agreement with Aburuman (2016) conducted a study entitled " The Impact of Administrative Empowerment on Creativity Improvement among the Workers of Jordanian Public Administration Institute" and stated that there was significance difference level in the workers' tendencies towards creativity improvement. Also, Al-Nouh et al., (2014), who conducted a study entitled " Primary School EFL Teachers' Attitudes towards Creativity and Their Perceptions of Practice, English Language Teaching " found that teachers' attitudes towards creativity and perceptions were high level.

Moreover, Al Zoubi (2016) who conducted a study entitled " The Impact of Administrative Decentralization in Administrative Creativity Applied Study in Islamic Banks in Jordan" found that majority of them tends to think with familiar routine at work to accomplish their duties. Also, Saleh et- al., (2013) revealed in their study that more than two thirds of them agree that nurses thinking limited to in fixed limits that imposed by the familiar routine.

Concerning staff nurses' level of productivity in work, the result of present study revealed that there was highly statistically significant improvement in staff nurses' level of productivity immediate post program and three months follow up the program compared to preprogram scores. From the researcher's opinion, Training program for staff nurses was effective as it improved their creativity and accordingly increased their productivity in work through looking for ways to improve their work force, and the way to complete the tasks, using the talents, time, and expertise of other people on my team to help get the work done. This result was supported by Jokari etal. (2012) who conducted a study entitled "Study the Effect of Creativity and Innovation on Nurses' Productivity in Taleghani Hospital (Case Study in Abadan of Iran)" and indicated that creativity and innovation play important roles in nurses productivity.

This result was consistent with Holland, McIntosh (2012) who said that Training programs for new employees increased their productivity. Also, Abdulla (2014) conducted a study entitled" The Effect of Time Management Educational Program for Newly Baccalaureate Graduate Nurses on Their Productivity " and reported that there was high statistically significant improvement in level of the newly baccalaureate graduate nurses 'productivity after intervention both immediate post program and follow up after three months compared to preprogram. 
Regarding Correlation between level of creativity, attitude toward creativity, level of productivity and experience, qualification of studied staff nurses during immediate post program phase, the result of the present study showed that there was a positive highly statistically significant correlation between level of creativity, attitude toward creativity, level of productivity and experience, qualification of studied staff nurses during immediate post program phase. From the researcher opinion, with increase in years of experience, nurse nurses face many problems and situations and resolve them effectively with their creativity skills which they acquired gradually from dealing with different issues and accordingly their productivity increase. Also, having high qualification enable nurses to demonstrate creativity which they learned through their education in their work leading to increased productivity.

This finding was congruent with saleh etal. (2013) who indicated that there was positive correlation between staff nurses' level of creativity and their qualification and experience. In the same line, Abdulla (2014) reported that there was positive statistically significant correlation between newly baccalaureate graduate nurses ' productivity level immediately post program and their years of experience. While there was no statistically significant correlation between newly baccalaureate graduate nurses ' productivity level both immediately post program and follow up after three months with their education.

Regarding Correlation between level of creativity, attitude toward creativity and level of productivity of studied staff nurses during immediate post program phase, the result of the present study showed that there was a positive highly statistically significant correlation between level of creativity, attitude toward creativity and level of productivity. This could be attributed to the success of productivity in work depends on staff creativity.

This finding was supported by Johnson (2009) who conducted a study entitled "Individual creativity and its association to individual productivity in the workplace" and concluded that a positive and significant relationship exists between individual creativity and individual productivity in project driven manufacturing and service organizations in the United States.

\section{Recommendation}

The findings of the study suggest that:

- Policymakers, nurse educators, nursing and hospital managers should provide a nurturing environment that is conducive to creative thinking, giving the nurses opportunity for flexibility, creativity, support for change, and risk taking for increasing productivity.

- Providing continuous training programs to develop leaders and nurses' knowledge which helps in improving their creativity, and provide incentives for creative activities.

- Conducting Periodical assessment of nurses` knowledge to detect subjects and areas to be covered in education courses of training to improve their productivity.

- Nursing faculties should integrate creative thinking education in study courses.

- Replication of the study on other categories of nursing staff is highly recommended to achieve generalizable results.

\section{Conclusions}

There was a positive highly statistically significant correlation between level of productivity and level of creativity and attitude toward creativity immediate post program. In addition, there was a positive highly statistically significant correlation between level of creativity, attitude toward creativity, level of productivity and experience, qualification of studied staff nurses during immediate post program phase.

\section{Acknowledgements}

The researchers would like to express gratitude and appreciations to (102) staff nurses who participated in this study for their effective cooperation.

\section{References}

i. Abdulla, N. (2014): The Effect of Time Management Educational Program for Newly Baccalaureate Graduate Nurses on Their Productivity, doctorate thesis, faculty of nursing, Benha university.

ii. Aburuman, N. (2016): The Impact of Administrative Empowerment on Creativity Improvement among the Workers of Jordanian Public Administration Institute, International Journal of Business and Social Science, 7(1), Pp: 182-190.

iii. Al Zoubi, M., (2016): The Impact of Administrative Decentralization in Administrative Creativity Applied Study in Islamic Banks in Jordan, Pp: 59-116, Available at www.hrmars .com/admin/ pics / 1809.pdf.accessed in 13-122016.

iv. Al-Nouh, N., Abdul-Kareem, M. and Taqi, H., (2014): Primary School EFL Teachers' Attitudes towards Creativity and Their Perceptions of Practice, English Language Teaching; Canadian Center of Science and Education, 7( 9), Pp:74-83.

v. Al-Srour, N. and Al-Oweidi, A. (2013): The Level of creativity among management employees, academic staff and artistes and its relationship with gender, practical experience and age.4(3):p 185-188

vi. Ariffin, R., Daud, F., Ariffin, R, Rashid, N., and Badib, A. (2011): Profile of Creativity and Innovation Among Higher Learning Institution Students in Malaysia, World Applied Sciences Journal, 36 (41), Pp: 36- 41. 
vii. Bruise, W. and Zahiyya, D. (2016): Impact of organizational creativity on the job performance in the corporation. Fourth scientific symposium research: creativity in the business world -Research and Development Center on Human Resources - Rammah - Jordan, 81 - 96.

viii. Chan, Z. (2013): A systematic review of creative thinking/ creativity in nursing education. Nurse Educ. Today 33 (11), 1382-1387. http:/ / dx.doi.org/ 10.1016/j.

ix. Chegani, M. (2016): The Effects of Organizational Intelligence and Creativity on Technological Innovation: A Case Study of The Manufacturing Firms In Iran, Arabian Journal of Business and Management Review , 5(7), Pp:14-34.

x. Dietrich, A. and Haider, H. (2015): Human Creativity, Evolutionary Algorithms, and Predictive Representations: The Mechanics of Thought Trials. Psychonomic Bulletin \& Review, 22(4), Pp: 897-915.

xi. Dlouhy, D.(2012): Undergraduate students`attitudes toward creativity. The Faculty of the College of Education University of Houston.From; https:/ / uh-ir.tdl.org/ uh-ir/ bitstream/ handle/ 10657/ 747/ DLOUHYDISSERTATION2012.pdf?sequence=1\&isAllowed=y Dul, J. Ceylan, and Jaspers, F. (2011): Knowledge Worker Creativity and the Role of the Physical Work Environment." Human Resource Management 50 (6): 715- 734.

xii. El-Shahat, M. (2014): The Effectiveness of Implementing Clinical Supervision Models on Head Nurses' Performance and Nurses' Job Satisfaction, unpublished Doctorate thesis , faculty of nursing , Benha university.

xiii. Farsi, Z., Habibi , H. and Lashkari , M.(2014) : Relationship between productivity and burnout in nurses of military xiv. hospitals in Tehran, J Arch Mil Med, 2(1) : e16276.

xv. Finkelman, A., Kenner, C. (2013): Professional nursing concepts: Competencies for quality leadership, 2nd ed., Jones \& Bartlett Publishers, USA, pp. 32-36, 283-284.

xvi. Finkler, S., Jones, C., Kovner, C. (2013): Financial management for nurse managers and executives, 4th ed., Elsevier Saunders, St. Louis, pp.301-306.

xvii. Gapar, Drazena and Mabic, Mirela (2014): Creativity in higher education. Economic and social development: Book of Proceedings. Varazdin Development and Entrepreneurship Agency (VADEA).

xviii. Holland, A. and McIntosh, B. (2012): Optimizing productivity, quality and efficiency in community nursing, British Journal of Community Nursing, 17(6): 258-264.

xix. Isfahani, S., Hosseini, A., Khoshknab, F., Peyrovi H, and Khanke H. (2015): Exploring Nurses' Creativity Consequences in Clinical Settings: A Qualitative Study, Journal of Health Promotion Management, 4 (1), P:1.

xx. Ivanovici, T.(2016): Attitudes Towards Creativity And The Creative Industries In Romania, Pp: 295-304. Avialable at www .asecu.gr/ files/ Romani a Proceedings / 32.pdf . accessed in 15-11-2017.

xxi. Jääskeläinen and Laihonen. (2013): Subjective Productivity Measurement ... aspects of knowledge worker performance.https:// www.researchgate.net/ publication/ 266866216_Subjective_Productivity_Measurement

xxii. Jabra, M. (2014):Managerial Patterns of Leadership and Its Relation to Innovation Management Theory Using Grid, Pp:5-20. Avialable at www.pdffactory.com.accessed in 1-12-2016.

xxiii. Jenkins, P. and Welton, J. (2014): Measuring direct nursing costs per patient in the acute care setting. Journal of Nursing Administration, 44(5), 257-262

xxiv. Johnson, M. (2009): Individual creativity and its association to individual productivity in the workplace, Doctorate thesis, University of Phoenix.

xxv. Jokari, M., Jorfi, H., and Ebadi, G.(2012):Study the Effect of Creativity and Innovation on Nurses' Productivity in Taleghani Hospital (Case Study in Abadan of Iran), Interdisciplinary Journal Of Contemporary Research In Business, 4(4), Pp:1055-1066.

xxvi. Kelly, P. and Tazbir, J. (2013): essentials of nursing leadership \& management, 3rd ed., Cengage Learning, USA, pp. 236-238, 319-320.

xxvii. Kim, B. and Hyunjae Y., (2015): Level of Creativity and Attitudes Toward an Advertisement, Creativity Research Journal, 27, 2,Pp: 133-138 http:/ / www.tandfonlin e. com/ loi / hcrj20.

xxviii. Kohr, L., Hickey, P. and Curley, M. (2012): Building a nursing productivity measure based on the synergy model: First steps, the American Journal of Critical Care, 21(6) pp. 420-431.

xxix. Maarouf, A. (2017): Career changing as perceived by nurses and its effect on their satisfaction, Master Thesis, Faculty of Nursing , Benha University, p. 45.

xxx. Malik, N. and Dhar, R. (2016): Authentic Leadership and its impact on extra role behavior of nurses- the mediating role of psychological capital and moderating role of autonomy. Pers. Rev. in press.

xxxi. Marasingha, U. (2012): Road to excellence incredible 5s for productivity improvement, 1st ed., Friesen Press Victoria, Canada, pp. 15-20

xxxii. Marquis, B. \& Huston, C. (2015): Leadership roles and management functions in nursing theory and application, 8th ed., Wolters Kulwer / Lippincott Williams \& Wilkins, Philadelphia, pp. 302-312.

xxxiii. Massy, W. F., Sullivan, T. A., \& Mackie, C. (2013):Improving measurement of productivity in higher education. Change, January/ February.

xxxiv. Murad, Ait Mohammed. (2016): International Conference on Creativity and Creativity in Business - R \& D Center Human Resources - Ramah - Jordan, Amman, 124-137.nedt.2012.09.005.

xxxv. Panatik, A., Katiminb, F. \&Shaari, R. (2016):The Effect of Personal Factors on Creativity among Research Officers in Malaysia, Journal of Advanced Research in Social and Behavioral Sciences , 2(1), Pp: 33-48.

xxxvi. Pujiriyanto , Samsi Haryanto , Mulyoto and Dewi Rochsantiningsih (2016):Effectiveness of EntrepreneurshipProject Based Learning Model to Improve Creativity Using Holistic Perspective (The Four P's). Business \& Entrepreneurship Journal, 5, (2).http:// www.scienpress.com/Upload/ BEJ/Vol\%205_2_1.pdf 
xxxvii. Roussel, L. (2011): Management and leadership for nurse administrators, 6th ed., Jones and Bartlett publishers, USA, pp. 419-430.

xxxviii. Saleh, N., El Sayed, M., Ghallab,S., \& AbdAlla, S., (2013):Nurse Leaders' Behaviors, and Its Effect on Nurses Creativity and Attitude Toward Change Main Assiut University Hospital, Journal of American Science, 9(12), Pp:906:912.

xxxix. Silvia, P. Wigert, B. Reiter-Palmon, R. and Kaufman, J. (2012): Assessing Creativity With Self-Report Scales: A Review and Empirical Evaluation. University of Nebraska at Omaha, bwigert@unomaha.edu.

xl. Tabarestani, M. Shoorideh, F. Jahani, M.A,. Poor, M. N. and Majd, H.A . (2014): Creativity and effective factors onhospital nurses creativity. Scientific Journal of Pure and Applied Sciences 3(8): p 741-747.www.Sjournals.com

xli. Taylor,R. (2013):Creativity at work: Supercharge Your Brain and Make Your Ideas Stick. https:/ / books.google.com.eg/ books?id=Ckob6zCjlGwC\&dq=Attitude+toward+creativity+questionnaire\&hl=ar\&so urce $=$ gbs navlinks $\mathrm{S}$

xlii. Valentine, S., L. Godkin, G. Fleischman, and Kidwell R.(2011). "Corporate Ethical Values, Group Creativity, Job Satisfaction and Trunover Intention: The Impact of Work Context on Work Response." Journal of Business Ethics 98: 353- 372. 